\title{
Klasik ve Modern Yapı Elemanları Kullanılması Durumunda Isı İletim Katsayısının Değişimi ile Minimum Yalıtım Kalınlığının Tayini
}

\author{
Determination of Minimum Insulation Thickness with the Change of Heat Conduction \\ Coefficient in the Use of Classic and Modern Building Elements
}

\author{
Kadir GELIȘ ${ }^{1, a}$, Faruk YEȘiLDAL ${ }^{* 2, b}$ \\ ${ }^{1}$ Bolu Abant Izzet Baysal Üniversitesi, Mühendislik Fakültesi, Makine Mühendisliği Bölümü, 14030, Bolu \\ ${ }^{2}$ Atatürk Üniversitesi, Mühendislik Fakültesi, Makine Mühendisliği Bölümü, 25240, Erzurum
}

\author{
• Geliş tarihi / Received: 23.04.2020 • Düzeltilerek geliş tarihi / Received in revised form: $24.06 .2020 \quad$ • Kabul tarihi / Accepted: 30.06 .2020
}

\begin{abstract}
$\ddot{\mathbf{O} z}$
Bu çalışmada Türkiye'deki 4 derece gün bölgesi için farklı duvar yapı elemanları (tuğla, bims ve gaz beton) örnek olarak seçilmiş, seçilen bu yapı malzemeleri için Türkiye piyasasında halen satışı yapılan farklı yalıtım malzemelerinin 1S1 iletim katsayısı aralığı $(0.025-0.060 \mathrm{~W} / \mathrm{mK})$ göz önünde bulundurularak uygulanması gereken minimum yalıtım kalınlıkları belirlenmiştir. Bu sayede farklı derece gün bölgeleri için minimum yalıtım kalınlığı malzeme türünden bağımsız bir hale getirilerek, 1sı iletim katsayısı tabanlı bir seçim önerilmiştir. Hesaplamalar 1sı, su, ses ve yangın yalıtımcıları derneğinin (izoder) TS 825 standartları kapsamında oluşturdukları "İzoder TS 825 Hesap Programı” ile yapılmıştır. Yapılan hesaplar neticesinde 1. Derece gün bölgesinde minimum yalıtım kalınlığı 1sı iletkenlik katsayısına ve yapı elemanına bağlı olarak $2-7 \mathrm{~cm}$ arasında değişirken, 2. Derece gün bölgesinde $2-8 \mathrm{~cm}$ arasında, 3 . Derece gün bölgesinde 3-10 cm arasında, 4. Derece gün bölgesinde 4-13 cm arasında olduğu hesaplanmıştır.
\end{abstract}

Anahtar kelimeler: Farklı Duvar Yapı Elemanları, Isı Yalıtımı, Isı İletim Katsayısı, TS 825

\begin{abstract}
In this study, different wall components for in four different degree days in Turkey (bricks and gas concrete) chosen as a sample, heat transfer coefficient range of selected these structures still available for sale in Turkey market for materials made of different insulating materials (0.025 to $0.060 \mathrm{~W} / \mathrm{mK})$ Taking into consideration the minimum insulation thicknesses to be applied were determined. In this way, a minimum insulation thickness is made independent from the material type for different degree day regions, and a selection based on heat transmission coefficient is proposed. Calculations were made with the "Izoder TS 825 Calculation Program" created by the heat, water, sound and fire insulators association (izoder) within the scope of TS 825 standards. As a result of the calculations, minimum insulation thickness varies between $2-7 \mathrm{~cm}$ depending on the thermal conductivity coefficient and building element in the 1 st degree day region, 2-8 cm in the $2 \mathrm{nd}$ degree day region, $3-10 \mathrm{~cm}$ in the $3 \mathrm{rd}$ degree day region, 4 . It is calculated that the degree is between $4-13 \mathrm{~cm}$ in the day zone.
\end{abstract}

Keywords: Different Wall Building Elements, Thermal Insulation, Heat Conduction Coefficient, TS 825

\footnotetext{
*b Faruk YEŞiLDAL, fayesildal@agri.edu.tr, Tel: (0472) 21598 63, orcid.org/0000-0002-7307-3556

${ }^{\mathrm{a}}$ orcid.org/0000-0001-8612-2233
} 


\section{Giriş}

İnsan nüfusunun hızlı artışı, teknolojinin ilerlemesi ve sanayileşmenin ivmelenmesi ile birlikte enerjiye artan talep ve enerji yoğunluğu her geçen gün artış göstermektedir. Ekonomik kalkınma, enerjiye olan talebi artırır. Enerjinin genellikle yenilenemeyen doğal kaynaklardan ve cari açık oluşturan ithal kaynaklardan elde edilmesi dezavantaj oluşturmaktadır. Küresel enerji ihtiyacının önemli bir bölümünü inşaat sektörü oluşturmaktadır. Türkiye'de hacim ısıtma ve soğutmanın toplam bina enerji tüketimine oranı \% 35 civarındadır (Yaman ve Şengül, 2015). Nüfus artışı, kentleşme ve yaşam standartlarının iyileşmesiyle konut arzının ve buna paralel olarak enerji tüketiminin de gittikçe artacağı öngörülmektedir. Bunun yanında enerji ithalatına ve sınırlı enerji kaynaklarımıza artan bağımlılık enerji odakl1 düşünmemizi gerektirmektedir. Bunun en iyi yolu enerjiyi verimli kullanmaktır. Son yıllarda sürekli artan enerji maliyetleri, enerji verimli binalar kavramına yönelik eğilimleri artırmaktadır. Dış duvar 1sı yalıtım uygulaması, binalarda enerji tasarrufu elde etmek için yaygın bir yaklaşımdır. Enerji verimliliğinin artırılması için konut ve kamu binaları çok büyük bir potansiyele sahiptir. Bina dış duvarının uygun tasarımı ve seçimi alan 1sitma ve soğutma yüklerini azaltabilir. $\mathrm{Bu}$ hem 1sitma yükünün azaltılması ve buna bağlı olarak iklim değişikliği (sera gazı) etkilerinin azaltılmasına da yardımcı olur (Bynum, 2000).

Ülkemizde enerji verimliliği iyileştirmesi için bina derecelendirme programları (enerji kimlik belgesi) yapılmaktadır. $\mathrm{Bu}$ ayrıca teşvik edilmektedir. 5627 Sayılı Enerji Verimliliği Kanunu ve Binalarda Enerji Performans1 Yönetmeliğine göre enerjinin ve enerji kaynaklarının etkin ve verimli kullanılması gereklidir (URL-1). 1 Ocak 2020 itibarı ile binalarda enerji kimlik belgesi zorunlu hale getirildi. Buna yönelik olarak bina enerji derecelendirmelerinin yaygınlaşmasıyla enerji verimliliği finansmanı da teşvik edilirse enerji tasarrufunun daha erişilebilir olacağını öngörmekteyiz.

Literatürde konut 1sitmasinda kullanılan duvar tipleri, 1s1 yalıtım malzemeleri, optimum yalıtım kalınlıkları, geri ödeme süresi analizi, nem ve yangın dayanıklılığı, çevresel etkiler, yalıtımın uygulama şekli gibi konularda yapılan çalışmalar aşağıda özetlenmiştir.
Türkiye'de binalar büyük miktarda enerji tüketiminden sorumludur ve muazzam enerji tasarrufu potansiyeline sahiptir. Uygulamadan önce daha doğru sonuçlara sahip olmak ve sürecin farklı yönlerini de dikkate almak gerekir. $\mathrm{Bu}$ çalışmada araştırmacılar (Ashrafian vd., 2016) Türkiye'nin üç farklı iklim bölgesinden seçtikleri şehirler için (Antalya, İstanbul ve Erzurum) aynı geometriye ancak farklı kaplama özelliklerine sahip üç vaka çalışması yapısını analiz ettiler. Bu iklimlerdeki vaka çalışması referans binalarının enerji simülasyonlarını uygulanabilir çözümlerini tanımlamak için ABD Enerji Bakanlı̆̆ (DOE) lisans1 altında yaygın olarak kullanılan bir simülasyon yazilımı olan EnergyPlus yoluyla gerçekleştirdiler. Soğuk iklimin dışında, maksimum enerji tasarrufu sağlayan eylemlerin geri ödeme süresi ve küresel maliyet konuları göz önüne alındığında arzu edilmeyeceğini belirttiler. (Fertelli, 2013), Türkiye'de yaygın olarak kullanılan farklı duvar tiplerinin (taş, tuğla, beton ve bims) optimum yalıtım kalınlıkları, enerji tasarrufu ve geri ödeme süreleri üzerindeki etkisini altı farklı yakıt türü (LPG, elektrik, akaryakıt, kömür, doğal gaz ve jeotermal enerji) için değerlendirdi. Bir başka çalışmada (Özel, 2011), dinamik termal koşullar altında farklı yapı malzemelerine sahip bina duvarlarının termal performansını inceledi ve optimum yalitım kalınlıklarını belirledi. Çalışmada Elazı̆̆ ili şartlarında, güney yönündeki bir dış duvar ele alınarak yalıtımsız ve yalıtılmış duvar yapıları için beton, briket, tuğla, blok bims ve AAC (otoklavlı gözenekli beton) bloktan yapılmış bina duvarlarının 1sıl performansını belirledi. Yalıtım malzemesi olarak ise XPS ve EPS kulland. Y1ll1k soğutma ve 1sitma iletim yüklerini, düzenli periyodik koşullar altında kapalı sonlu fark yöntemi kullanarak hesaplanır. Sonuçta beş farklı yap1 malzemesine ve iki farklı yalıtım malzemesine bağlı olarak optimum yalıtım kalınlıklarının 2- $8.2 \mathrm{~cm}$, enerji tasarruflarının 2.78- $102.16 \$ / \mathrm{m}^{2}$ ve geri ödeme sürelerinin ise 1,32-10,33 yıl arasında değiştiğini gösterdi. $\mathrm{Bu}$ çalışmada araştırmacılar (Ucar ve Balo, 2010) Türkiye'nin dört iklim bölgesinden dört şehir (Elazığg, Bitlis, Şanlıurfa ve Mersin) için dış duvarın optimum yalıtım kalınlığını, 10 yıllık enerji tasarrufu ve geri ödeme sürelerini, beş farklı yakıt türü (kömür, doğalgaz, fuel-oil, LPG ve elektrik) ve dış duvarlara uygulanan dört farklı yalıtım malzemesi (EPS, XPS, Siding ve taş yünü) için hesapladılar. Enerji maliyet tasarruflarının şehre ve yalıtım malzemelerine bağlı olarak 4.2$9.5 \$ / \mathrm{m}^{2}$ arasında değiştiğini gördüler. En düşük tüketime enerji kaynağı olarak doğal gaz kullanıldığ 1 durumda ulaştılar. 2,25 yıl ile en 
yüksek geri ödeme süresi değerine Mersin'de, en düşük değere ise Bitlis'te ulaştılar. İran'da yapılan bir başka çalışmada araştırmacılar (Rosti vd., 2020) tüm iklim bölgelerinde dış duvarın ideal yalıtım kalınlığını, enerji tasarrufunu ve yatırım geri ödeme süresini belirlediler. Çalışmada gri tuğla duvar ve üç farklı modern duvar (İçi boş kil blok, LECA blok ve AAC blok) için inceleme yaptılar. Tüm iklim bölgelerinden sekiz şehir seçerek, iletim yükünü belirlemek için sayısal bir çözümle birlikte yaşam döngüsü maliyet analizi yöntemini kullanarak optimizasyon yaptılar. Sonuçta, İran'da kullanılan modern duvarlardan biri olan AAC blok duvarında 1S1 yalitımı uygulamasının bazı şehirlerde ekonomik olmadığını belirttiler. İran'daki maksimum yalıtım kalınlığının $4 \mathrm{~cm}$ 'den fazla olmadığını ve bunun da diğer ülkeler için bildirilen değerlerden çok daha düşük olduğunu belirttiler. $\mathrm{Bu}$ çalışmada (Kalhor ve Ememinejad, 2020) 1s1 direnci, maliyet, nem ve yangına dayanıklılık gibi farklı kriterlere dayalı olarak binalardaki geleneksel is1 yalıtım malzemeleri üzerine kapsamlı bir genel bakış ve analiz sunulmaktadır. Her yalıtım tipinin avantajları ve dezavantajları tartışılmaktadır. Yalıtım malzemesini niteliksel olarak optimize etmek için bina kaplama tipine ve sistemine dayalı öneriler verdiler. Çalışmada tasarımcılar ve uygulayıcılar için daha pratik çözümler ve değerlendirme araçları sağlamak için ağırlıklı olarak geleneksel malzemeleri incelediler. Ancak yeni yalıtım malzemelerini de kısaca tartıştılar. Ayrıca, yalıtım uygulamasını nicel olarak optimize etmek için, COMcheck programını kullanarak enerji analizlerini küresel olarak bilinen iki enerji koruma koduna dayanarak yaptılar. Macaristan'da yapılan bu çalışmada araştırmacılar (Kisilevicz vd., 2019) Nyiregyhaza kasabasinda bulunan deneysel bir konut binasında yapılan araştırmaların ön sonuçlarını ve analizlerini sunmaktadır. Bu makalede yazarlar, aktif yalıtım sisteminin yaygin olarak kullanılan standart pasif yalıtım sistemlerinin ne ölçüde yerini alabileceği sorusunu cevaplamaya çalıştılar. Aktif 1sı yalıtımının diş duvarın yalıtım parametrelerini önemli ölçüde geliştirdiği sonucuna vardılar. Analiz edilen duvarın eşdeğer termal geçirgenliği $U_{\text {eq }}$ yerel iklim koşullarına bağlıydı ve Kasım ayında $0.047 \mathrm{~W} / \mathrm{m}^{2} \mathrm{~K}$ ve Mart ayında $0.11 \mathrm{~W} / \mathrm{m}^{2} \mathrm{~K}$ olurken standart geçirgenlik değerini $0.282 \mathrm{~W} / \mathrm{m}^{2} \mathrm{~K}$ elde ettiler. Elde edilen olumlu araştırma sonuçları, NZEB (sıfıra yakın enerji yapısı) binalarında yenilikçi bir sistemin uygulanmasının temeli olması gerektiğini tavsiye ettiler. Ülkemizde yapılan bir çalışmada araştırmacılar (Uygunoğlu ve Keçebaş, 2011) duvar malzemesi ve enerji tüketim maliyetleriyle birlikte toplam maliyeti en aza indiren optimum kalınlık, tasarruf ve geri ödeme süresini tahmin etmek için Afyonkarahisar'daki binaların dış duvarları için yaşam döngüsü maliyet analizi yaptılar. Uzun vadeli ve mevcut dış hava sıcaklığı kayıtlarını dikkate alarak, derece/gün değerlerini kullanmış ve birim alan başına çeşitli duvar tipleri (bir, iki, üç ve dört sıralı delikli tuğla, gaz beton) ve yakıt türleri (akaryakıt, doğalgaz, kömür ve elektrik) için binanın yıllık enerji ihtiyacının değişimi araştırmışlardır. Sonuç olarak, en yüksek enerji tasarrufunu 4 suralı içi boş bloklar kullanarak elde ettiler. Ayrıca, tüm iklim bölgeleri için en uygun yakıtların elektrik ve akaryakıt olduğunu gördüler. Ancak, atmosferik kirlilik önemli bir husus olduğundan doğalgazın daha iyi bir seçim olacağını belirttiler. Yalıtım malzemelerinin sinıflandırıldığ 1 bir inceleme çalışmasında araştırmacılar (Aditya vd., 2017) kapalı hücre köpügüu, vakum yalıtım paneli, gaz dolu panel, aerojel ve faz değişim malzemesi (PCM) de dahil olmak üzere son teknoloji ürünü yalıtım malzemelerini gözden geçirdiler. Bir başka çalışmada ise (Papadopoulos, 2005) daha sık kullanılan yalıtım malzemelerini sinıflandırdı.

Is1 yalıtımının amac1, 1S1 kaybını veya kazancını azaltacak ve sonuç olarak enerji maliyetinin düşmesine yol açacak enerji tasarruflu malzemeler kullanılarak enerjinin verimli kullanılmasıdır. Çeşitli araştırmacılar tarafindan isı yalıtım malzemeleri ve uygulamaları üzerine birçok çalışma yapılmıştır, fakat literatür taramasından da anlaşılacağı üzere yapılan hesaplar hep yalıtım malzemesi ve duvar yapı elemanı tabanlıdır. $\mathrm{Bu}$ çalışmada 1sı yalıtım piyasasında kullanılan farklı yalıtım malzemelerine ilişkin detaylı bir araştırma yapılmış ve bu 1sı yalıtım malzemelerinin isıl iletkenlik katsayıları aralıkları belirlenmiştir. Piyasada bulunabilirlik, uygulama kolaylığ gibi durumlar göz önünde bulundurularak $13.5 \mathrm{~cm}$ kalınlığında tuğla, $17.5 \mathrm{~cm}$ kalınlığında bims ve gaz beton için dört farklı derece gün bölgesinde minimum 1s1 yalıtım kalınlıkları 1s1 iletim katsayıları parametre olacak şekilde belirlenmiştir. $\mathrm{Bu}$ sebeple bu çalışmada Türkiye'de en çok uygulanan duvar yapı elemanları temel alınarak 1S1 iletim katsayısı tabanlı bir minimum yalitım kalınlığ 1 hesabı yapılmıştır. Bahsi geçen hesaplamalar İzoder TS 825 Hesap Programı kullanılarak TS 825 Standartları (URL-2) dikkate alınarak yapılmıştır. 


\section{Materyal ve Metot}

\subsection{Materyal}

Yalıtım malzemeleri uygulanabilirlik, fiyat, tedarik, yangın güvenliği, çevre ve halk sağlığı açısından değerlendirilirken, endüstrinin gelecekteki gelişmeler için belirlediği amaçlara da uygun olmalıdır. Bu amaçlar; mevzuat, piyasa ve güvenlik çerçevesinde bütünleşik etkileriyle birlikte değerlendirilmelidir. Bu çalışmada TS 825 binalarda 1s1 yalıtım kurallarının öngörmüş olduğu 4 farklı derece gün bölgesi için önerilen maksimum 1s1 transfer katsayı değerlerinden (U) yola çıkılarak her bölge için ısı iletim katsayısının parametre olduğu minimum yalıtım kalınlığ hesaplanacaktır. Binalarda kullanılan duvar yapı elemanlarının çok farklı olması ve farklı uygulamalar olması sebebiyle Türkiye'de en çok uygulanan duvar yapı elemanlarından olan tuğla ve gaz beton standart yap1 elemanı olarak tercih edilecek, bims ise modern yapı elemanı olarak ele alınacaktır. Bu farklı yapı elemanlarının piyasada en çok bulunan tipi ve kalınlığı (tuğla için 13.5 $\mathrm{cm}$, gaz beton ve bims için $17.5 \mathrm{~cm}$ ) için minimum yalıtım kalınlığ 1 değeri bölge bazlı olarak önerilecektir.

$\mathrm{Bu}$ çalışmada kullandığımız duvar kesiti konfigürasyonları (Şekil 1) ve duvarlarda kullanılan yapı elemanları (Şekil 2) detaylı olarak verilmiştir.

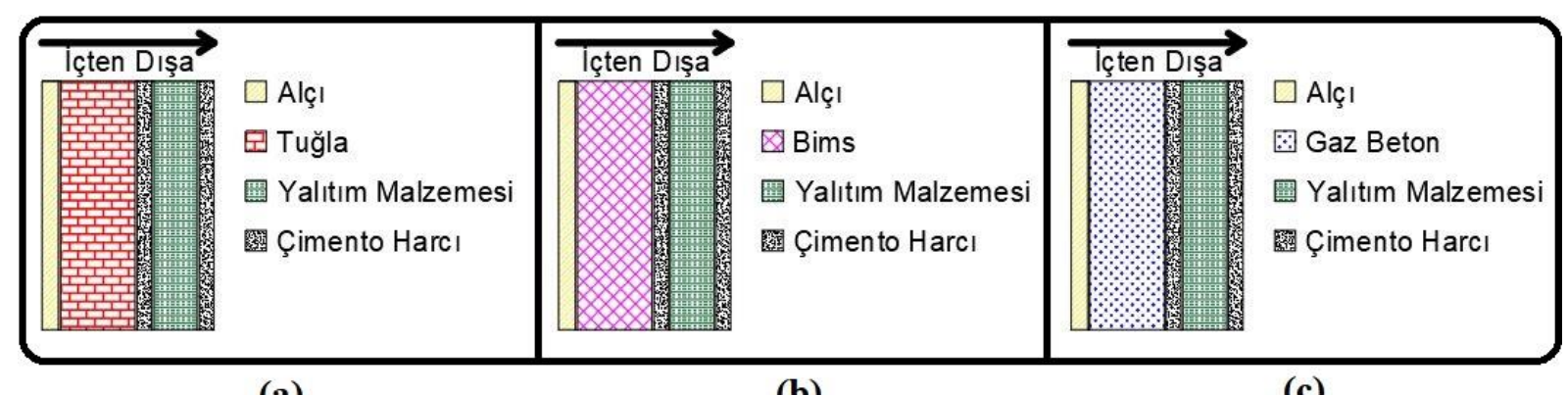

(a)

(b)

(c)

Şekil 1. Duvar kesitini oluşturan malzemeler, (a) Tuğla Duvar, (b) Bims Duvar, (c) Gaz beton Duvar

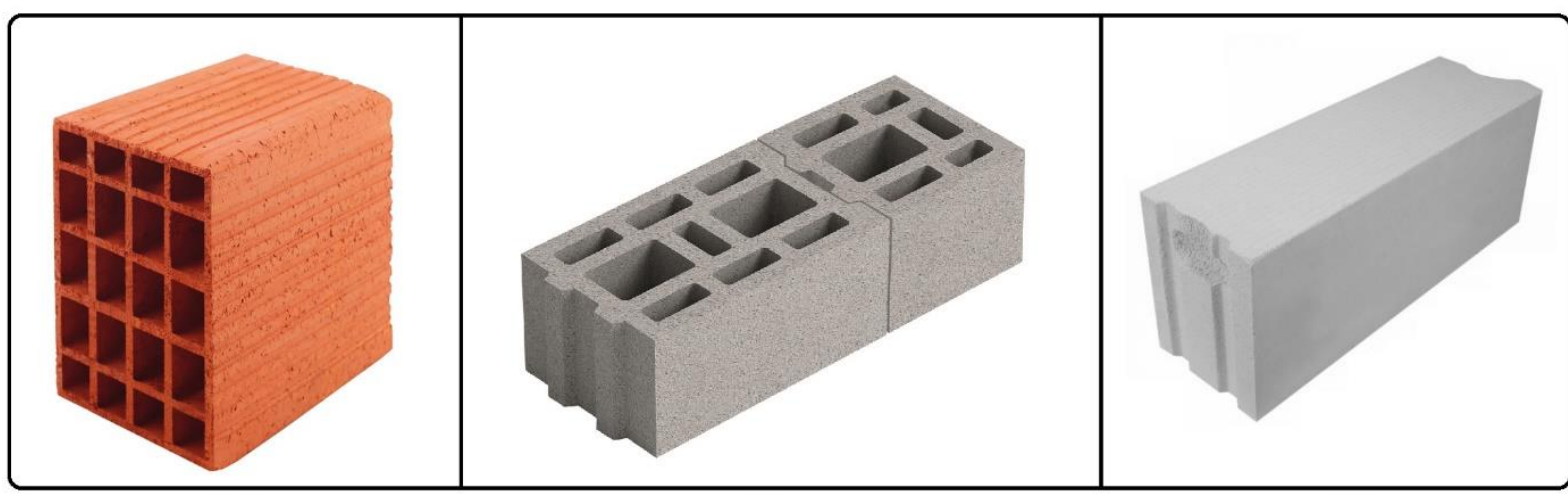

(a) (b)

Şekil 2. Duvarda kullanılan yapı elemanları (a) Tuğla (b) Bims (c) Gaz beton

Aşağıda verilen tabloda (Tablo 1) çalışmada kullandığımız duvar kesitini oluşturan malzemeler ve kalınlıkları verilmiştir.

Tablo 1. Duvar kesitini oluşturan malzemelerin kalınlıkları

\begin{tabular}{ll}
\hline Malzeme Cinsi & Kalınlık (cm) \\
\hline Alçı & 2 \\
Gaz Beton & 17.5 \\
Bims & 17.5 \\
Tuğla & 13.5 \\
Yalıtım Malzemesi & Her bölge için minimum değer hesaplanacaktır \\
Çimento Harcı (Toplam) & 1.5 \\
\hline
\end{tabular}


Çalışmada üç farklı duvar yapı elemanı için hesap yapılmıştır. Bunlardan ilki tuğla, ikincisi bims ve üçüncüsü gaz beton 'dur. Bu tercihler 4 farklı bölgenin iklim koşulları, piyasada bulunabilirlik ve uygulama kolaylığı açısından tercih edilmiştir. Üç yapı elemanının da piyasada en çok tercih edilen ve bulunan kalınlıkları için hesaplamalar yapılmıştır. Çalışmanın temel amacı herhangi bir 1S1 yalıtım malzemesi işaret etmeden, 4 farklı bölge için 1sı iletim katsayısı tabanlı minimum 1sı yalıtım malzemesi kalınlıklarının belirlenmesidir. Yalıtım malzemeleri için 1sı iletim katsayısı aralığı $0.025 \mathrm{~W} / \mathrm{mK}$ ile $0.090 \mathrm{~W} / \mathrm{mK}$ olmasına rağmen $0.060 \mathrm{~W} / \mathrm{mK}$ değerinden yüksek 1s1 iletkenliğe sahip malzemeler ahşap içerikli malzemelerdir. $\mathrm{Bu}$ yüzden yangın dayanımı ve cepheye uygulanabilirlik açısından değerlendirilerek 1s1l iletkenlik değerleri 0.025$0.060 \mathrm{~W} / \mathrm{mK}$ aralığında seçilmiştir (Tablo 2).

Tablo 2. Piyasada kullanılan yalıtım malzemelerinin ısıl iletkenlik aralığı (URL-3)

\begin{tabular}{|c|c|c|}
\hline Malzeme Adı & Standart & $\begin{array}{ll}\text { Isıl } & \text { Iletkenlik } \\
(\mathrm{W} / \mathrm{mK}) & \\
\end{array}$ \\
\hline 1.Ahşap Yünü Levhalar & TS EN 13171 & $0.060-0.090$ \\
\hline $\begin{array}{llll}\begin{array}{l}\text { 2.Yerinde } \\
\text { Malzemeler }\end{array} & \text { İmal } & \text { Edilmiş } & \text { Köpük } \\
\end{array}$ & DIN 18159 & \\
\hline 2.1 Poliüretan (PUR) & DIN 18159-1 & $0.035-0.040$ \\
\hline 2.2 Reçine-formaldehit köpügü (UF) & DIN 18159-2 & $0.035-0.040$ \\
\hline \multicolumn{3}{|l|}{ 3.Sentetik Köpük Malzemeler } \\
\hline 3.1 Expande Polistiren Köpük(EPS) & TS 7316 EN 13163 & $0.035-0.040$ \\
\hline 3.2 Extrude Polistiren Köpük(XPS) & TS 11989 EN13164 & $0.030-0.040$ \\
\hline 3.3 Poliüretan Sert Köpük(PUR) & TS 10981 ve TE EN 13165 & $0.025-0.040$ \\
\hline $\begin{array}{l}\text { 4.Fenol Reçinesinden Sert Köpük(PF) } \\
\text { Levhalar }\end{array}$ & TS EN 13166 & $0.030-0.045$ \\
\hline $\begin{array}{l}\text { 5.Mineral ve Bitkisel lifli 1S1 yalıtım } \\
\text { malzemeleri(Camyünü, taşyünü gibi) }\end{array}$ & TS 901-1 EN 13162 & $0.035-0.050$ \\
\hline 6.Cam Köpüğü & TS EN 13167 & $0.045-0.060$ \\
\hline 7. Ahşap Lifli Isı Yalıtım Levhaları & TS EN 13168 & $0.035-0.070$ \\
\hline 8. Mantar Yalıtım Levhaları & TS 304 EN 13170 & $0.045-0.055$ \\
\hline
\end{tabular}

TS 825 Binalarda 1S1 yalitım kuralları standartlarında Türkiye 4 farklı derece gün olarak değerlendirilmektedir. 1. Derece gün Türkiye'de en sicak iller iken 4. Derece gün illeri Türkiye'nin en soğuk illeridir. TS 825 standardında yer alan derece gün bölgelerine göre illerimiz Şekil 3'de sunulmuştur.

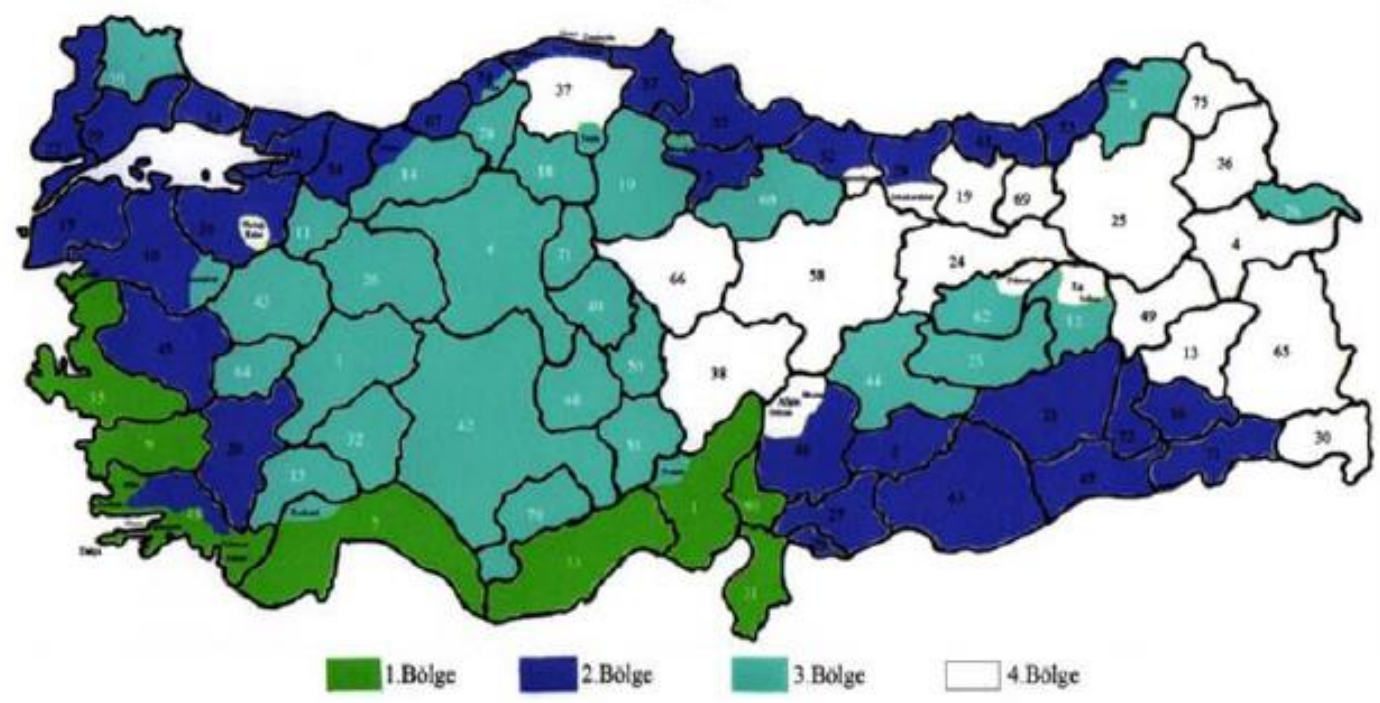

Şekil 3. Derece gün bölgelerine göre illerimiz (URL-3) 
Derece / Gün bölgelerine göre toplam 1sı transfer katsayısı (U) değerleri Tablo 3'te verilmiştir.

Tablo 3. Derece / Gün bölgelerine göre tavsiye edilen maksimum U değerleri (URL-3)

\begin{tabular}{lllll}
\hline BÖLGE & $\mathrm{U}_{\text {duvar }}$ & $\mathrm{U}_{\text {tavan }}$ & $\mathrm{U}_{\text {taban }}$ & $\mathrm{U}_{\text {pencere }}$ \\
\hline DG1 & 0.7 & 0.45 & 0.7 & 2.4 \\
DG2 & 0.6 & 0.4 & 0.6 & 2.4 \\
DG3 & 0.5 & 0.3 & 0.45 & 2.4 \\
DG4 & 0.4 & 0.25 & 0.4 & 2.4 \\
\hline
\end{tabular}

\subsection{Hesap Yöntemi}

TS 825 standartlarında farklı derece gün bölgeleri esas alınarak duvar için tavsiye edilen U değerleri dikkate alınarak 3 farklı yapı bileşeni için hesap yapılmış ve değişken ısıl iletkenlik katsayılarına bağlı olarak minimum yalıtım kalınlıkları belirlenmiştir.

\section{Toplam Isı Transfer Katsayısı Hesaplama}

a) Toplam 1s1 geçiş katsayısı (U)

$R_{\text {top }}^{\prime}=R_{\text {iç }}^{v}+\sum R_{\text {ilet }}^{v}+R_{\text {dus }}^{v}$

$R_{\text {ilet }}^{v}=\frac{L}{k \cdot A}$

$$
U=\frac{1}{R_{\text {top }}^{r}}
$$

Burada; U: yapı bileşenlerinin toplam $1 \mathrm{~S} 1$ geçiş katsayısı $\left[\mathrm{W} / \mathrm{m}^{2} \mathrm{~K}\right], R_{\text {topp }}^{\prime}$ duvar kesitini oluşturan elemanların iletim ve taşınım yoluyla oluşturduğu eşdeğer devre direnci $\left[\mathrm{m}^{2} \mathrm{~K} / \mathrm{W}\right], R_{i \zeta ̧}^{r}$ iç ortamın taşınım direnci $[\mathrm{K} / \mathrm{W}], R_{\text {dıฐ్ }}^{r}$ dış ortamın taşınım direnci $\left[\mathrm{m}^{2} \mathrm{~K} / \mathrm{W}\right], R_{\text {ilet }}^{\prime}$ ise duvar kesitini oluşturan her bir eleman için hesaplanan iletim direncidir $\left[\mathrm{m}^{2} \mathrm{~K} / \mathrm{W}\right]$. Formüldeki taşınım dirençleri TS 825'in öngördüğg̈ şekilde Tablo 4'den okunmuştur.

Tablo 4. Hesaplanmış taşınım dirençleri (URL-3)

\begin{tabular}{|c|c|c|c|}
\hline \multirow{2}{*}{$\begin{array}{l}\text { Sira } \\
\text { no }\end{array}$} & \multirow[t]{2}{*}{ Yapı bileşeni tipi } & \multicolumn{2}{|c|}{ Yüzeysel 1sıl iletim direnci ${ }^{1)} 2$} \\
\hline & & $\mathrm{R}_{\mathrm{i}}\left(\mathrm{m}^{2} \mathrm{~K} / \mathrm{W}\right)$ & $\mathrm{R}_{\mathrm{e}}\left(\mathrm{m}^{2} \mathrm{~K} / \mathrm{W}\right)$ \\
\hline 1 & Diş duvar & \multirow{4}{*}{0.13} & 0.04 \\
\hline 2 & $\begin{array}{l}\text { Arkadan havalandırılan giydirme cepheli diş duvarlar, 1S1 yalıtımı } \\
\text { yapılmayan tavan arasını ayıran alçak duvarlar }\end{array}$ & & 0.08 \\
\hline 3 & $\begin{array}{l}\text { Daireler arasındaki ayırıcı duvarlar, merdiven duvarı, farklı } \\
\text { kullanım amaçlı çalışma odalarını ayıran duvarlar, sürekli olarak } \\
\text { 1sıtılmayan mekânlara bitişik bölme duvarı, ısı yalıtımlı tavan } \\
\text { arasına bitișik alçak duvar }\end{array}$ & & 3) \\
\hline 4 & Toprak temaslı diş duvar & & 0 \\
\hline 5 & $\begin{array}{l}\text { Bir yaşama mekânının dış hava ile sınırını oluşturan yatay veya } \\
\text { eğimli, yukarıda yer alan (havalandırılmayan çatı) tavan veya çatı }\end{array}$ & \multirow[b]{2}{*}{0.13} & 0.04 \\
\hline 6 & $\begin{array}{l}\text { Kullanılmayan bir tavan arası veya havalandırılan bir mekân } \\
\text { altındaki tavan (havalandırılan çatı kabuğu) }\end{array}$ & & 0.08 \\
\hline 7 & $\begin{array}{l}\text { Daireler arası ayırıcı taban veya farklı kullanım amaçlı çalışma } \\
\text { odalarını ayıran taban }\end{array}$ & & \\
\hline 7.1 & Aşağıdan yukarıya 1sı akışı olması halinde & 0.13 & \multirow[t]{2}{*}{ 3) } \\
\hline 7.2 & Yukarıdan aşağıya 1sı akışı olması halinde & 0.17 & \\
\hline 8 & Bodrum tavanı & \multirow{3}{*}{0.17} & 3) \\
\hline 9 & $\begin{array}{l}\text { Bir yaşama mekânının dış hava ile sınırını oluşturan çıkma } \\
\text { tabanları }\end{array}$ & & 0.04 \\
\hline 10 & $\begin{array}{l}\text { Altında bodrum olmayan bir yaşama mekânının zemine oturan } \\
\text { tabanı }\end{array}$ & & 0 \\
\hline
\end{tabular}

1) Basitleştirmek amacıyla bütün durumlarda $R_{i}=0.13 \mathrm{~W} / \mathrm{m}^{2} \mathrm{~K}$ ve 4 ve 10 . Sıradaki durumlar hariç olmak üzere $R_{e}$ $=0.04$ değerleri hesaplamalarda kullanılabilir.

2) Yapı elemanlarından buhar geçişinin tahkiki ve sınırlandırılması ile ilgili hesaplamalarda kullanılacak iç ve dış yüzeysel $1 \mathrm{~s}$ iletim direnci için $\mathrm{R}_{\mathrm{i}}=0.25 \mathrm{~W} / \mathrm{m}^{2} \mathrm{~K}$ ve $\mathrm{R}_{\mathrm{e}}=0.04 \mathrm{~W} / \mathrm{m}^{2} \mathrm{~K}$ değerleri kullanılmalıdır.

3) Yapı bileşeninin iç mekânda yer alması durumunda hesaplamalarda iç ve dış yüzey 1sıl iletim direnç değerleri aynı kabul edilmelidir. 


\section{Bulgular}

Binalarda enerji verimliliğinin artırılması için en etkili yollardan biri $1 \mathrm{~S}$ yalıtımıdır. Bu çalışmada TS 825 standartları kapsamında Türkiye'deki dört farklı derece/gün bölgesi için 1sı iletim katsayısı baz alınarak farklı dış duvar yapı malzemeleri kullanılarak minimum yalıtım kalınlıları belirlenmiştir. Bulgular, incelenen yap1 malzemelerine göre 1sıl iletkenlik-minimum yalıtım kalınlığı grafikleri halinde sunulmuştur.
Şekil 4 ülkemizdeki tüm derece gün bölgelerinde yap1 elemanı olarak tuğla kullanıldığı durum için minimum yalıtım kalınlığının 1sıl iletkenlikle değişimini göstermektedir. Tüm bölgelerde 1s1l iletkenliğin artmasıyla minimum yalıtım kalınlığ da artmaktadır. Ayrıca en soğuk bölgede (DG4) minimum yalıtım kalınlığ $13 \mathrm{~cm}$ değerine ulaşırken, en sıcak bölgede (DG1) bu değerin 3 cm’ye kadar düştüğü görülmektedir.

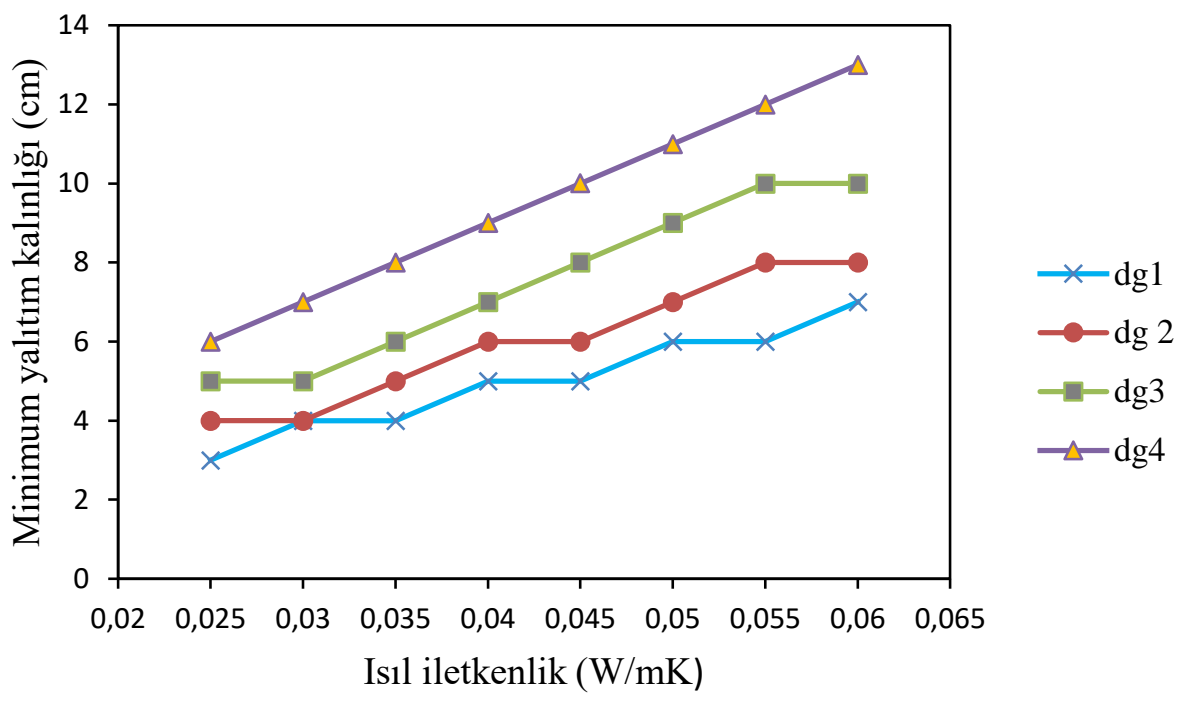

Şekil 4. Tuğla için yalıtım kalınlığının 1sıl iletkenlik ile değişimi

Şekil 5'te ülkemizdeki tüm derece gün bölgelerinde yapı elemanı olarak bims kullanıldığ 1 durum için minimum yalıtım kalınlığının 1s1l iletkenlikle değişimi görülmektedir. Tüm bölgelerde 1sıl iletkenliğin artmasıyla minimum yalıtım kalınlığı da artmaktadır. Ayrıca en soğuk bölgede (DG4) minimum yalıtım kalınlığı $12 \mathrm{~cm}$ değerine ulaşırken, en sicak bölgede (DG1) bu değerin $3 \mathrm{~cm}$ 'ye kadar düştüğü görülmektedir.

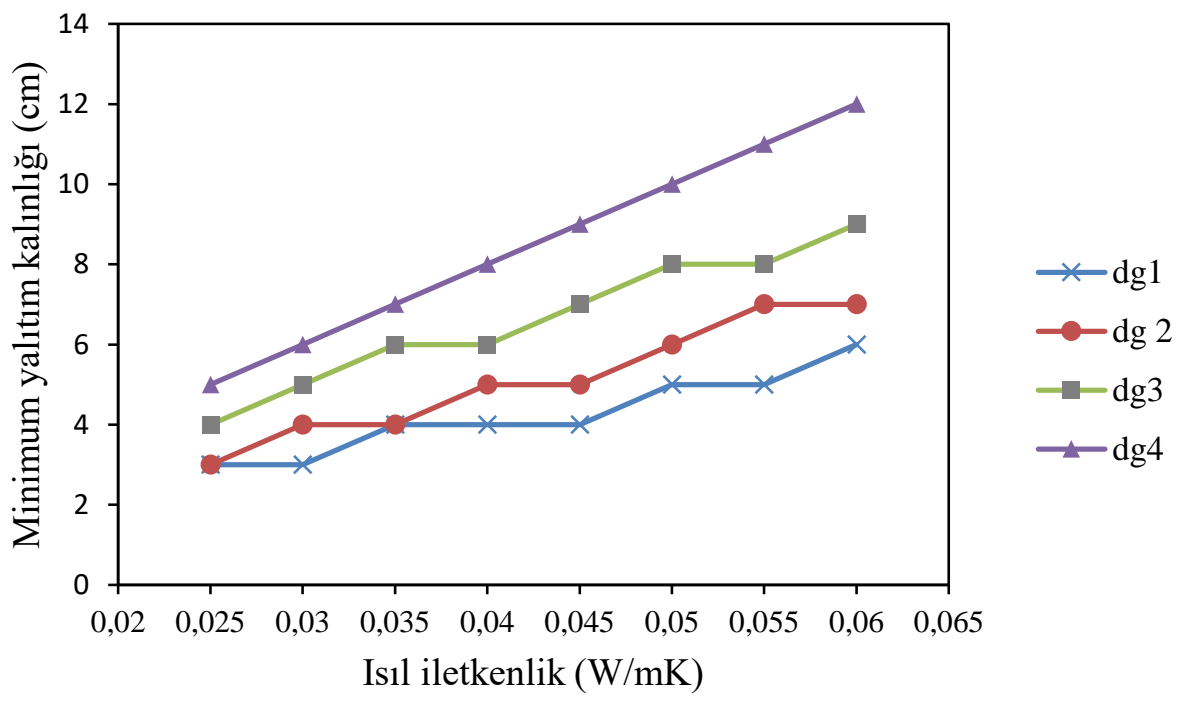

Şekil 5. Bims için yalıtım kalınlığının 1sıl iletkenlik ile değişimi 
Şekil 6'da ülkemizdeki tüm derece gün bölgelerinde yap1 elemanı olarak gaz beton kullanılması halinde minimum yalıtım kalınlığının 1sıl iletkenlikle değişimini göstermektedir. Tüm bölgelerde 1sıl iletkenliğin artmasıyla minimum yalıtım kalınlığı da artmaktadır. Ayrıca en soğuk bölgede (DG4) minimum yalıtım kalınlığı $10 \mathrm{~cm}$ değerine ulaşırken, en sicak bölgede (DG1) bu değerin $2 \mathrm{~cm}$ 'ye kadar düştüğü görülmektedir. Minimum yalıtım kalınlığının en küçük değerleri gaz beton yapı malzemesi için elde edilmiştir.

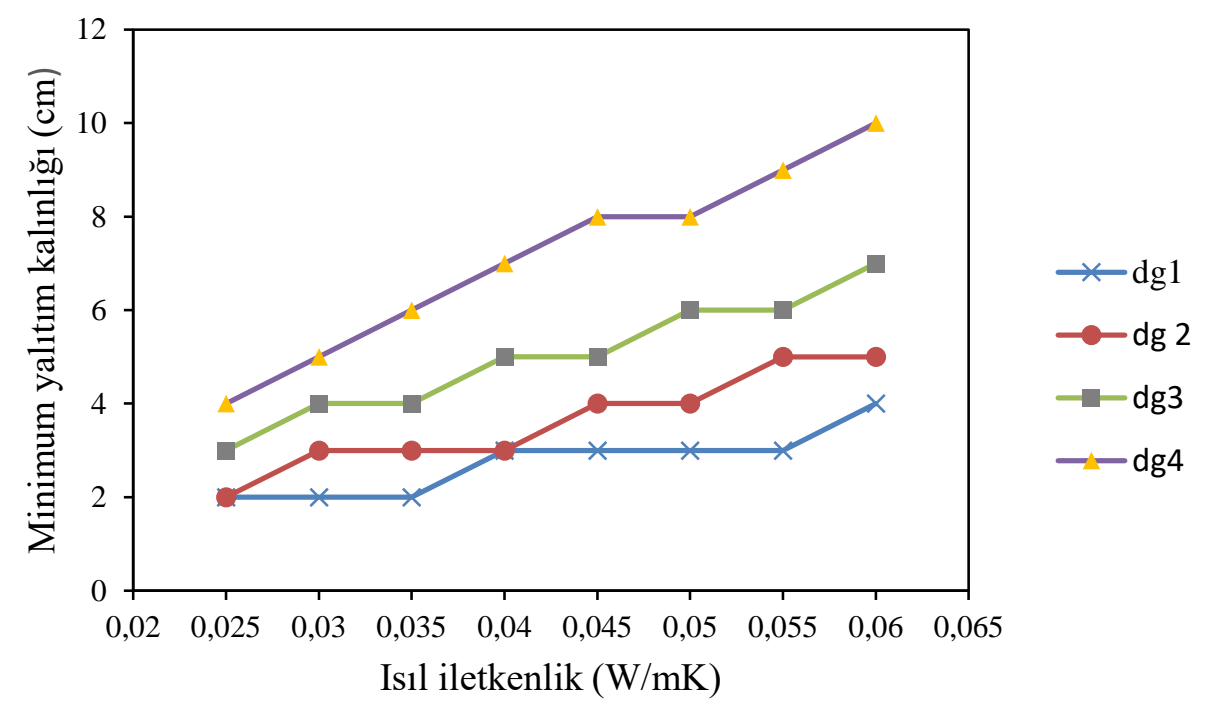

Şekil 6. Gaz beton için yalıtım kalınlığının 1sıl iletkenlik ile değişimi

\section{Tartışma ve Sonuçlar}

Bu çalışmada Türkiye'nin tüm iklim bölgeleri için farklı yapı malzemeleriyle yapılan dış duvarın minimum yalıtım kalınlıkları hesaplanmıştır. Çalışmada yalıtım malzemesinin geniş bir aralığında 1sı iletim katsayıları baz alınarak malzeme türünden bağımsız bir hale getirilerek 1s1 iletim katsayısı tabanlı bir seçim önerilmiştir. Bu çalışmada elde edilen sonuçlar aşağıda maddeler halinde sunulmuştur.

- TS 825 programiyla yapilan hesaplar neticesinde DG1 bölgesinde minimum yalıtım kalınlığı 1sıl iletkenlik katsayısına ve yapı elemanına bağlı olarak 2-7 $\mathrm{cm}$ arasında değişirken, DG2 bölgesinde 2-8 $\mathrm{cm}$ arasında, DG3 bölgesinde $3-10 \mathrm{~cm}$ arasinda, DG4 bölgesinde ise $4-13 \mathrm{~cm}$ arasinda olduğu görülmüştür.

- Tüm bölgelerde 1s1l iletkenliğin artmasıyla minimum yalıtım kalınlığı da artmaktadır. Yap1 malzemesi için tuğla kullanıldığı durumda en soğuk bölgede (DG4) minimum yalıtım kalınlığ $13 \mathrm{~cm}$ değerine ulaşırken, en sicak bölgede (DG1) bu değerin $3 \mathrm{~cm}$ 'ye kadar düştüğü görülmüştür.
- Yap1 elemanı olarak bims kullanıldığı durumda en soğuk bölgede (DG4) minimum yalıtım kalınlığı $12 \mathrm{~cm}$ değerine ulaşırken, en sıcak bölgede (DG1) bu değerin $3 \mathrm{~cm}$ 'ye kadar düştüğü görülmektedir.

- Bina dış duvarında modern bir yapı elemanı olan gaz beton kullanıldığı durumda ise en soğuk bölgede (DG4) minimum yalıtım kalınlığ $10 \mathrm{~cm}$ değerine ulaşırken, en sicak bölgede (DG1) bu değerin $2 \mathrm{~cm}$ 'ye kadar düştüğü görülmektedir. Minimum yalıtım kalınlığının en küçük değerleri gaz beton yapı malzemesi için elde edilmiştir.

- Enerji tasarrufu tüm dünyada çevreyi ve doğal kaynakları korumayı hedefleyen bir strateji haline gelmiştir. Enerji verimliliğini artırmak ve kayıpları en aza indirmek için sürekli bir arayış vardır. Ayrıca binalarda 1sı yalıtımı; ekonomik, çevresel ve sosyal olarak inşaat sektöründe enerji tüketiminin azaltılması için önemli bir potansiyeldir.

- Ticari olarak birçok yalıtım malzemesi geliştirilmesine rağmen bazı ürünler termal, mekanik, sağlığa olumsuz etki ve uygulama zorluğu gibi durumlarla karşı karşıyadır, bu 
sebeple projelendirme yapilırken bütün kriterler göz önünde bulundurulmalıdır.

- Bina yalıtımı termal enerji talebinin azaltılarak enerji kaynaklarının verimli ve daha az tüketilmesine doğrudan katkı sağlayabilir.

- İnşaat yatırımları planlanırken mevcut duvar yapı elemanları ve yalıtım malzemesi çeşitleri de analiz edilerek çok yönlü bir analiz yapılması gereklidir.

- Hem ekonomik hem de çevresel faydaları da dikkate alınarak diş duvar konstrüksiyon malzemesinin seçimi ve sonunda 1s1 yalıtım malzemesinin kalınlığının ve türünün belirlenmesi birbiri ile ilişkili ve önemli konulardır.

- Is1 yalıtım projesi yapılan bölgede projelendirme yapılırken duvar bileşenlerinin duvar yap1 elemanları ve 1 s1 yalitım malzemeleri ile birlikte değerlendirilerek projelendirilmesi, ardından da kalınlıklarının belirlenmesi gereklidir.

- Yalıtım malzemesinin binaya uygulanmasının temel amac1 bina duvar kesitinin termal direncinin artırılarak ısıtma ve soğutma için gerekli enerji tüketimini azaltmaktır. Bunu yaparken uygun isıl iletkenlik değerine sahip malzemenin seçimi maliyet açısından önem arz etmektedir.

Bina yalıtımı yapmak tüketilen enerji miktarını azalttığı için aynı zamanda binaların yaydığı sera gazının olumsuz çevresel etkilerini azaltmaya katk1 sunmaktadır.

\section{Kaynaklar}

Aditya, L., Mahlia, T.M.I., Rismanchi, B., Ng, H.M., Hasan, M.H., Metselaar, H.S.C., Muraza, O. ve Aditiya, H.B., 2017. Review on Insulation Materials for Energy Conservation in Buildings. Renewable and Sustainable Energy Reviews, 73, 1352-1365.

Ashrafian, T., Yilmaz, A. Z., Corgnati, S. P. ve Moazzen, N., 2016. Methodology to Define Cost-Optimal Level of Architectural Measures for Energy Efficient Retrofits of Existing Detached Residential Buildings in Turkey. Energy And Buildings, 120, 58-77.
Bynum, R. T., 2000. Insulation Handbook, Mcgraw Hill Professional, 494p.

Kalhor, K. Ve Ememinejad, N., 2020. Qualitative and Quantitative Optimization of Thermal İnsulation Materials: Insights from the Market and Energy Codes. Journal Of Building Engineering, 30, 101275.

Kisilewicz, T., Fedorczak-Cisak, M. ve Barkanyi, T., 2019. Active Thermal Insulation as an Element Limiting Heat Loss Through External Walls. Energy and Buildings, 205, 109541.

Ozel, M., 2011. Thermal Performance and Optimum Insulation Thickness of Building Walls With Different Structure Materials. Applied Thermal Engineering, 31(17-18), 3854-63.

Papadopoulos, A. M. (2005). State of the Art in Thermal Insulation Materials and Aims for Future Developments. Energy and Buildings, 37(1), 77-86.

Rosti, B., Omidvar, A. Ve Monghasemi, N., 2020. Optimal Insulation Thickness of Common Classic and Modern Exterior Walls in Different Climate Zones of Iran. Journal Of Building Engineering, 27, 100954.

Ucar, A. Ve Balo, F., 2010. Determination Of The Energy Savings and The Optimum Insulation Thickness in the Four Different Insulated Exterior Walls. Renewable Energy, 35(1), 8894.

URL-1, www.resmigazete.Gov.Tr /Eskiler/ 2007/05/20070502-2.Htm. 20 Nisan 2020. (in Turkish)

URL-2, Turkish Standard 825 (Ts 825). Official Gazette Number 27019. Ankara; 2008.

URL-3, www.izoder.org.tr/Sayfa/30/Ts-825-HesapProgrami. 8 Nisan 2020.

Uygunoğlu, T. ve Keçebaş, A., 2011. Lcc Analysis for Energy-Saving in Residential Buildings With Different Types of Construction Masonry Blocks. Energy And Buildings, 43(9), 2077-85.

Uzun, İ., 2020. Istıtılan Mekanlarda İç ve Dış Ortam Sicaklıklarına Bağlı Mevsimsel Yoğuşma Analizi. Uluslararası Mühendislik Araştırma ve Geliştirme Dergisi, 12(1), 292-99 (in Turkish).

Yaman, Ö., Şengül, Ö., Selçuk, H., Çalıkuş, O., Kara, İ., Erdem, Ş. Ve Özgür, D., 2015. Binalarda Is1 Yalıtımı ve Isı Yalıtım Malzemeleri. Türkiye Mühendislik Haberleri (Tmh), 487(4), 62-75 (in Turkish). 